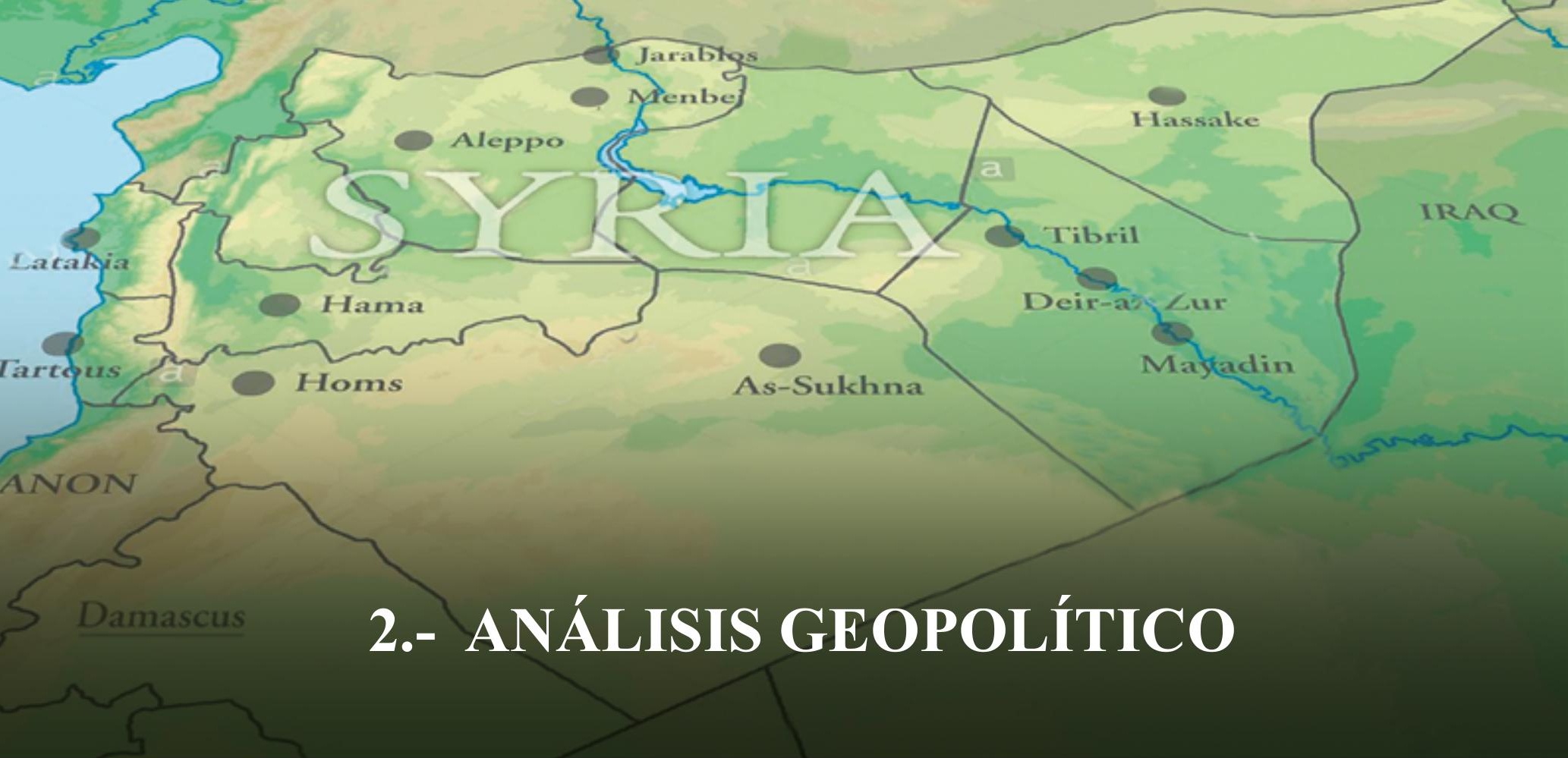

\title{
EL CONFLICTO SIRIO CAMBIOS EN EL EQUILIBRIO ESTRATÉGICO EN MEDIO ORIENTE
}

Grab. Francisco Armendáriz S. ${ }^{1}$

\begin{abstract}
RESUMEN
Además de la guerra civil interna que enfrenta a la mayoría suní apoyada por los yihadistas y la minoría chií en el gobierno de Basar al Assad, apoyada por Hezbolla; en la región se enfrentan diversos intereses de actores estratégicos Occidentales como Estados Unidos, Turquía e Israel, de la Liga Árabe como Arabia Saudita y Qatar frente a los intereses de Rusia, Irán y China, quienes influyen de manera directa e indirecta en el conflicto, cuyo desenlace podría cambiar el equilibrio estratégico en favor de Rusia e Irán.
\end{abstract}

La estabilidad en Medio Oriente en general y en Siria en particular dependerá del grado de influencia que puedan ejercer Estados Unidos y Rusia, en sus respectivos aliados para evitar que la situación se complique y desemboque en un enfrentamiento de las Fuerzas Armadas de Turquía y las de Siria y convertirse en un conflicto internacional de consecuencias impredecibles.

Palabras clave: Eje Rusia-Irán-Siria; Chiitas, Sunitas, Kurdos, Yihadistas; Eje Estados Unidos-Turquía, Arabia Saudita-Qatar, equilibrio regional; Israel, Hezbolla.

\begin{abstract}
In addition to the internal civil war facing the Sunni majority supported by the jihadists and the Shiite minority in the Basar al Assad government, supported by Hezbolla; in the region, various interests of Western strategic actors such as the United States, Turkey and Israel, of the Arab League such as Saudi Arabia and Qatar face the interests of Russia, Iran and China, who directly and indirectly influence the conflict, whose outcome could change the strategic balance in favor of Russia and Iran.
\end{abstract}

Stability in the Middle East in general and in Syria in particular will depend on the degree of influence that the United States and Russia can exert on their respective allies to prevent the situation from complicating and leading to a confrontation between the Turkish Armed Forces and those of Syria and become an international conflict of unpredictable consequences.

Keywords: Russia-Iran-Syria axis; Shiites, Sunnis, Kurds, Jihadists; Axis United States-Turkey, Saudi ArabiaQatar, regional balance; Israel, Hezbollah.

\footnotetext{
1 fjarmendariz1964@gmail.com

EJÉRCITO ECUATORIANO
} 


\section{Introducción}

Medio Oriente ha sido y será un escenario conflictivo debido a una confluencia de intereses contrapuestos de orden político, religioso y económico, en una región que, siendo la cuna de la civilización y origen de las tres religiones monoteístas de mayor influencia en la humanidad, hoy en día contiene la mayor reserva petrolera mundial; situación que complica aún más el equilibrio inestable de la región. En este sentido el conflicto sirio es de particular importancia para los países árabes y para las potencias mundiales en la búsqueda de un nuevo equilibrio regional que favorezca a sus intereses.

\section{Escenario del conflicto}

Siria es un país soberano del Oriente Próximo, en la costa oriental mediterránea, cuya forma de gobierno es la república unitaria semi presidencialista, actualmente sumida en una guerra civil. Comparte fronteras con Turquía por el norte, Irak por el este, Israel y Jordania al sur, y Líbano por el oeste, Siria es miembro de la Organización de las Naciones Unidas.

Siria posee una población de 20 millones de habitantes, la mayoría de los cuales hablan árabe. Además, la mayoría de la población profesa el islam, siendo el sunismo el grupo musulmán mayoritario. Entre los musulmanes no sunitas en Siria están los drusos, alawitas y chiitas. Hay en Siria minorías de las etnias asiria, armenia, turca y kurda junto a miles de refugiados palestinos.

Desde el año 1963 el Partido Baath Árabe Socialista, gobierna siria bajo la declaratoria de estado de emergencia y desde 1970 el presidente de Siria ha pertenecido a la familia Asad. En la actualidad el Presidente es Bashar al-Asad, hijo de Hafez al-Asad, quien rigió los destinos del país desde 1970 hasta su muerte en el año 2000.

\section{Gobierno y política}

Siria es una república desde 1963. En 1973 se aprobó en referéndum la Constitución que definía a Siria como República Democrática, Popular y Socialista, basada, entre otros, en el socialismo árabe, los principios de igualdad ante la ley, libertad religiosa y propiedad privada. En 2012 se aprobó por plebiscito una nueva Constitución.

Cada siete años se elige a un presidente, que debe ser musulmán; y cada cuatro, una Asamblea del Pueblo y un Consejo de Ministros. Según la Constitución, el presidente tiene poderes para nombrar y destituir a los vicepresidentes, al primer ministro y a los ministros. Es también comandante en jefe de las Fuerzas Armadas, secretario general del Partido Baath Árabe Socialista y presidente del Frente Nacional Progresista del país.

Los órganos legislativos son la Asamblea del Pueblo y los Consejos de Administración Local. Los tres poderes del Estado sirio son controlados por el Baaz, que tiene asegurada la participación decisiva en los poderes del Estado gracias a la Constitución del país.

Está permitida la participación de otros seis partidos políticos menores que junto al mayoritario Baaz integran el llamado, Frente Nacional Progresista (FNP), esos partidos son los únicos autorizados a expresar las ideas políticas de los ciudadanos sirios. Igualmente es el Partido Baaz el que domina el mencionado Frente, dichos partidos integran el Parlamento que es controlado directamente por el Presidente de la República, ya que el poder Ejecutivo se reserva la mayoría de las potestades legislativas y de revisión de las actividades del Legislativo.

La Constitución de Siria inviste al Partido Baath Árabe Socialista, de las funciones de liderazgo del gobierno del Estado y de la vida de la sociedad siria. El Presidente, que posee grandes facultades para ejecutar el gobierno, es elegido por siete años para cumplir sus funciones, además de ello es a su vez el Presidente del Partido Baath y el líder del Frente nacional progresista. El presidente de Siria además posee las facultades de designar a los ministros, declarar la guerra, proponer las leyes al poder Legislativo, y dirigir las Fuerzas Armadas. En el referéndum para la elección del Presidente en 2007, fue reelegido con el $97,62 \%$ de los votos Bashar al-Asad.

\section{Geografía}

En el país se distinguen, de oeste a este, tres regiones: en el oeste se encuentra una llanura litoral, separada del interior por el Yabal Ansariyya, una doble cordillera en cuyo interior se abren diversos valles; el centro del país está formado por una accidentada meseta con varios picos volcánicos que está recorrida de noreste a suroeste por una cordillera en la que se distinguen diversas formaciones: Yabal Abd al-Aziz, Yabal Visir, Yabal Buwayda, Yabal Saar, Yabal al Sarqi y Yabal Garbi.

La región del este está constituida por el valle del Éufrates. Este es el principal río que surca el país, que penetra por el norte y toma dirección sureste; también es importante su afluente Jabur y el Orontes en el oeste. En el extremo noreste la frontera con Turquía la forma 
el curso del Tigris. En la parte oeste del país el clima es mediterráneo, pero conforme se avanza hacia el este se vuelve más seco y caluroso.

De sur a norte, en el tercio oeste del país, fluye el río Orontes.

La población se concentra en los territorios situados en el oeste; la tasa de crecimiento vegetativo es muy alta. En cuanto a la economía, el país está en vías de desarrollo, aunque desde 1973, y debido a problemas políticos que le han hecho destinar parte de su presupuesto a gastos militares, la inflación ha frenado ese progreso.
Su agricultura, favorecida desde 1978 por la construcción de la presa de Tabka, que permite regar amplias superficies, se dedica prioritariamente al cultivo de cereales, algodón, olivos y hortalizas. Cuenta con ganadería ovina, caprina y bovina. De su subsuelo se extrae asfalto, sal gema, petróleo, fosfatos y gas natural. La industria, también en desarrollo, es principalmente textil, alimentaria, cementera, de construcción y de refinado de petróleo. En los últimos tiempos algunos países, como Rumania o la República Federal de Alemania, han hecho inversiones en sus industrias azucareras, de cemento y de fosfatos y gas natural; las extracciones de petróleo, sin embargo, no han dado los resultados esperados.

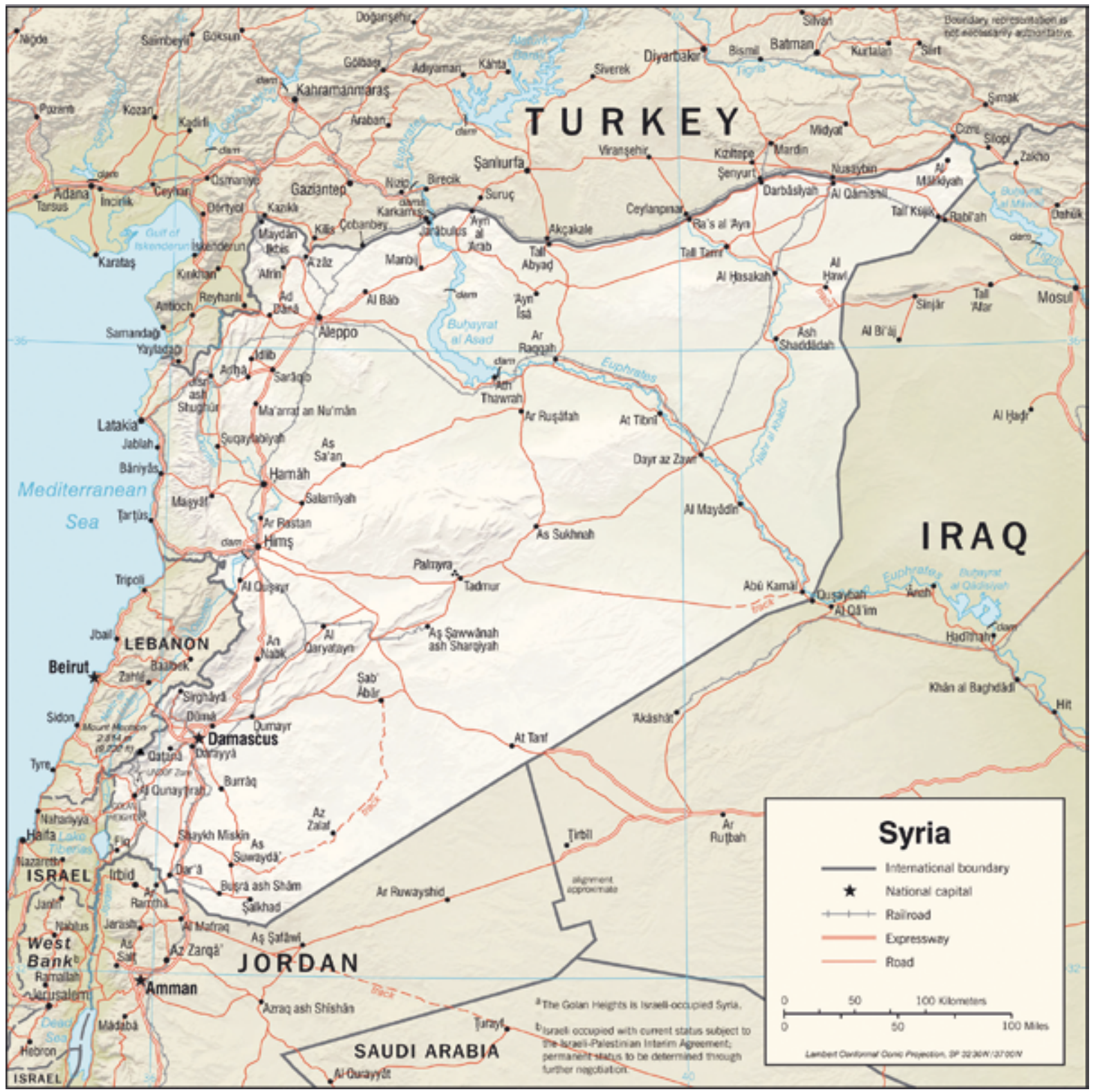

Figura 1. Mapa de Siria. 


\section{Economía}

La agricultura (trigo y algodón) genera el $27 \%$ del PIB y la ganadería, principalmente caprina y ovina va dirigida a la exportación de lana, posee reservas de gas natural, sal gema y fosfatos. Las industrias textil, alimentaria, metalúrgica y cementera suponen el $22 \%$ del PIB. Los derechos del paso de petróleo foráneo por los oleoductos que tiene el país, generan grandes ingresos para el gobierno y lo sitúan en una posición estratégica, entre el Medio Oriente y Europa.

\section{Demografía}

La población siria es de 19.043.000 habitantes, y una densidad de $99 \mathrm{hab} / \mathrm{km}^{2}$, que se concentra en su mayoría en territorios del oeste del país. La mayoría es de origen árabe (90,3\%).

La población se concentra en tres zonas geográficas: la franja litoral y sus relieves próximos, a lo largo del curso del río Éufrates y en la frontera norte con Turquía. El 51,8\% de los sirios viven en núcleos urbanos. El crecimiento del sector industrial y el éxodo rural han comportado un rápido desarrollo de las ciudades.

La más poblada es la capital Damasco, situada en la vertiente oriental de las montañas del Antilíbano. Le siguen en importancia Alepo, en el noroeste del país; Homs y Hama, a orillas del río Orontes; y Latakia, en la costa mediterránea.

Aunque se ha moderado, la pirámide poblacional siria aún evidencia una estructura joven: el 38,6\% de los habitantes es menor de 15 años. Este fenómeno se debe a una fecundidad de 3,32 hijos por mujer, que sitúa el crecimiento anual de la población sobre el 2,4\%. Si este comportamiento demográfico persiste, Siria duplicará el número total de sus habitantes en menos de treinta años.

\section{Salud}

El agua del grifo, está clorada, y además, es potable (en las poblaciones alejadas de las ciudades principales puede estar contaminada).

Hay riesgo de paludismo, y la enfermedad que se da al norte del país es la leishmaniasis. También, secundariamente, se da el tifus, fiebre recurrente, fiebre hemorrágica de Crimea-Congo, filariasis, fiebre tifoidea, y hepatitis A y B.

\section{Educación}

La educación preescolar en Siria es para los niños de tres años de edad y dura tres años. Es gratuita y no obligatoria.
Al cumplir los seis años de edad se ingresa en la educación primaria. Esta etapa dura seis años. Cuando se termina, se obtiene el certificado de educación primaria, si se ha aprobado.

Después, la sigue la educación intermedia, que dura tres años, y cuando se termina aprobada, el alumno consigue el diploma de educación intermedia, dependiendo del tipo de educación intermedia que se haya elegido (educación general o religiosa).

El siguiente paso es la educación secundaria general, y dura tres años. Durante el primer año tiene un contenido general para todos los alumnos; y al continuar con el segundo año se pueden escoger dos materias: ciencias, o letras; aunque también hay secundarias técnicas.

\section{Religión}

La religión islámica es predominante: los musulmanes obedecen principalmente a la ortodoxia suní, aunque también hay alawitas, chiíes, drusos e ismailitas. El cristianismo, en sus diferentes confesiones (ortodoxos, siríacos, maronitas, católicos de rito armenio, etc.), se circunscribe a las provincias periféricas y a algunos barrios urbanos. Además, cabe acotar que, a diferencia de otras naciones del Medio Oriente, en Siria se respeta la libertad de culto, por lo tanto, no hay enfrentamientos ni parcialismo entre cristianos e islamitas, incluso, las mujeres pueden transitar libremente por las calles, careciendo de cualquier tipo de velo islámico. Las fiestas cristianas del nacimiento de Jesús, 25 de diciembre, así como viernes Santo y domingo de Resurrección se celebran en todo el país como días de fiesta nacional.

\section{Situacion actual de las operaciones en Siria}

Desde el año 2010 Siria enfrenta una guerra interna motivada por la pretensión del Presidente Bashar alAsad, de mantenerse en el poder indefinidamente, las fuerzas gubernamentales que lidera reciben el respaldo económico y militar por parte de Rusia e Irán, quienes intervienen en el conflicto de manera directa mediante entrenamiento y el apoyo de unidades blindadas, aviación de combate y artillería antiaérea de última generación. Recibe además recibe apoyo político y militar por parte del partido libio de Hezbolla.

El respaldo político de China y Rusia en el seno del Consejo de Seguridad de las Naciones Unidas, ha evitado una intervención directa por parte de Estados Unidos y sus aliados de la OTAN.

Del otro lado las fuerzas rebeldes conformadas mayoritariamente por grupos opositores al régimen de Al Assar se aglutinan en el Ejército de Liberación Sirio ELS, más conocido por sus siglas en inglés FSA (Free 


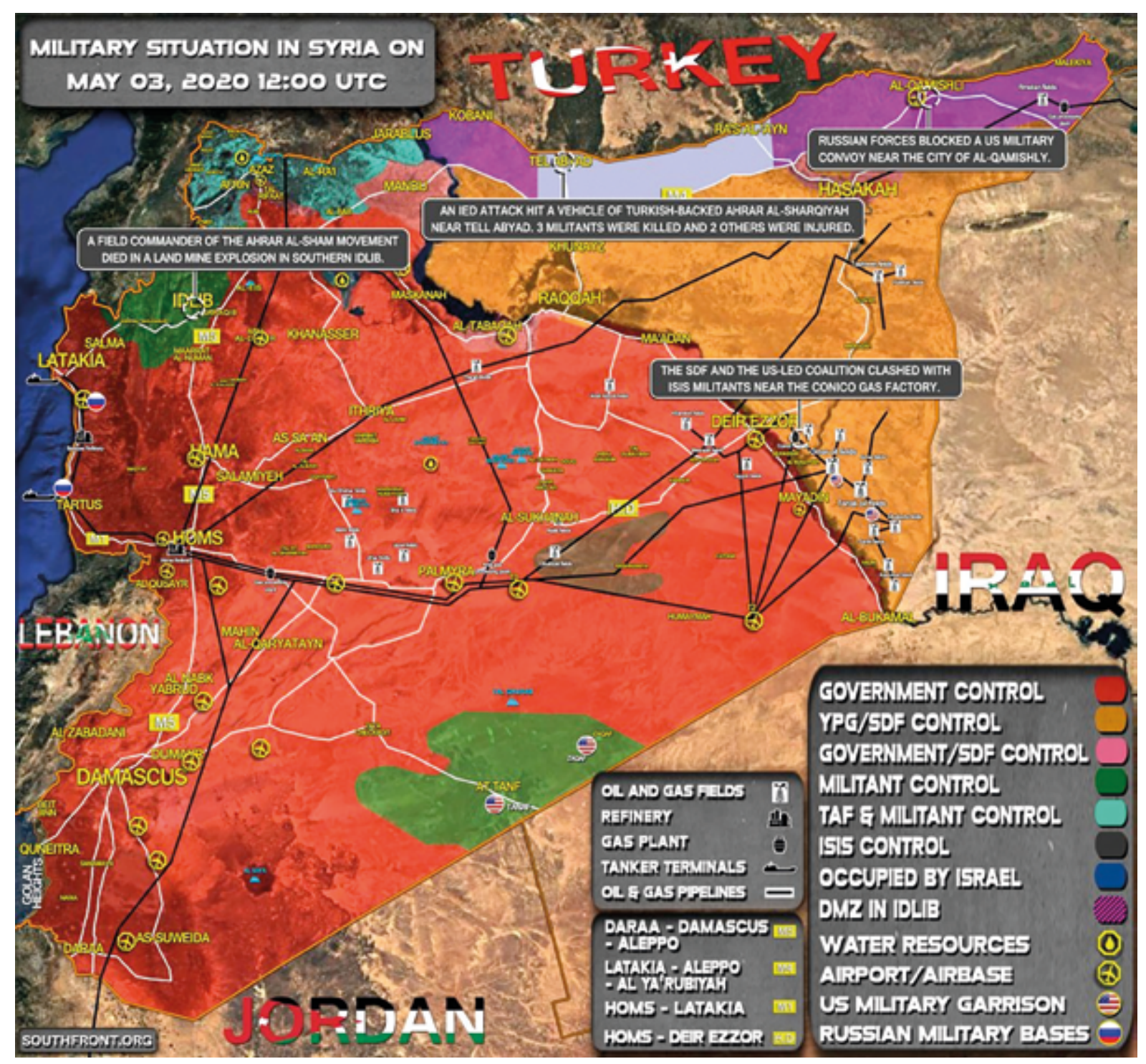

Figura 2. Situación Geopolítica de Siria.

Sirian Army), este grupo está apoyado militarmente por el Ejército de Turquía con unidades blindadas, misiles y artillería antiaérea, armas antitanque y sustentado logísticamente por Estados Unidos y sus aliados de la OTAN; quienes suministran armas municiones y equipo de combate, sin embargo la política exterior norteamericana, ha evitado involucrarse directamente en el conflicto y mantiene un apoyo encubierto a las acciones militares de Turquía y un apoyo logístico permanente a las fuerzas opositoras.

En los últimos días Estados Unidos retiró sus tropas de la parte norte de Siria, dejando en indefensión a los rebeldes kurdos aliados del PPK, que combatían a los islamistas radicales de ISIS y Al QAEDA. Ahora sin la presencia de las tropas norteamericanas, Turquía ha intensificado sus ataques hacia el ejército sirio y los rebeldes kurdos en el norte de Siria.

Grupos islamistas radicales como ISIS y Al QAEDA financiados por Arabia Saudita y Qatar, libran una guerra paralela independiente en contra del Ejército Sirio y los rebeldes kurdos.

Israel coordina sus acciones militares con Estados Unidos, reservándose el derecho de responder a los ataques que provengan desde Siria.

Arabia Saudí, apoya en forma encubierta las acciones de los grupos opositores al régimen, pero de una manera que no afecte su posición dentro de la Liga árabe.

\section{Países neutrales}

El resto de países se mantienen en suspenso a la espera del desarrollo de los acontecimientos. Egipto ha declarado su rechazo a la intervención de Turquía y ha calificado la presencia de sus tropas, como una violación abierta a la soberanía siria.

Los estados limítrofes como Jordania o Líbano sufren las consecuencias de la llegada de oleadas de refugiados sirios que huyen del conflicto. 


\section{Actores en el conflicto sus intereses}

\section{objetivos y poder relativo}

El mapa que se presenta a continuación resume en forma gráfica los diversos actores y sus relaciones de afinidad entre ellos. A pesar de que existen más actores en el conflicto se han analizado a aquellos que tienen pensamiento, intención e iniciativa estratégica, para influir en el conflicto de acuerdo a sus intereses.

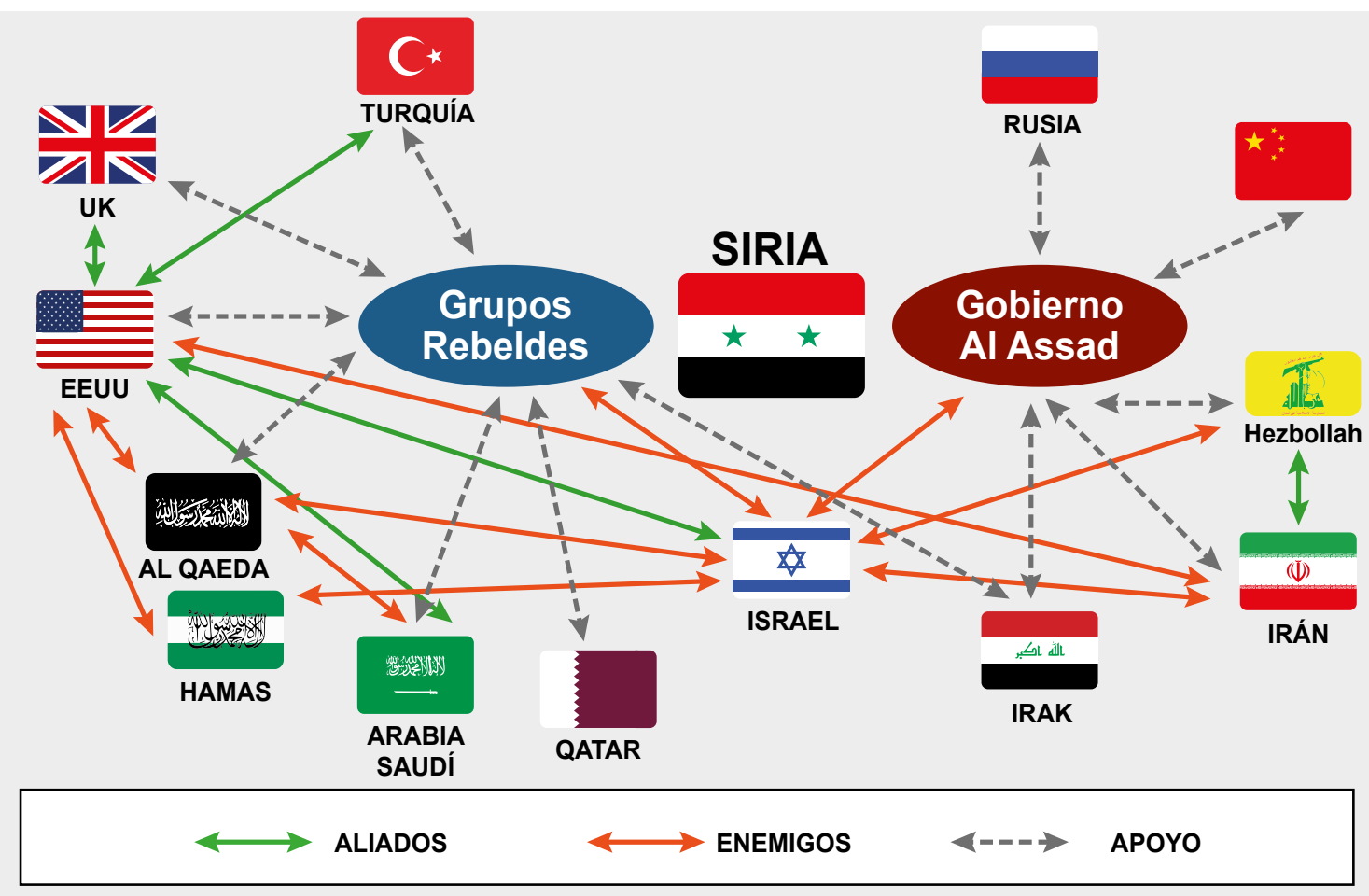

Figura 3. Actores involucrados en el Conflicto Sirio.

La hipótesis de trabajo sostiene que el equilibrio en Medio Oriente, depende de la permanencia en Siria del gobierno chiita de Bashar al Assad, debido a que un triunfo rebelde o un cambio de gobierno hacia la mayoría sunita, significaría el cambio en las relaciones de poder entre el eje Rusia, Irán, Siria y
Hezbolla y el eje Estados Unidos, Turquía, Arabia Saudita e Israel.

El cuadro que se presenta a continuación resume de manera simplificada los actores involucrados en el conflicto sirio, los intereses y objetivos que persiguen.

CUADRO DE ACTORES INTERESES Y OBJETIVOS EN EL CONFLICTO SIRIO (Fuente : Elaboración propia)

\begin{tabular}{l|l|l}
\hline \hline \multicolumn{1}{c|}{ ACTOR } & \multicolumn{1}{c}{ INTERESES } & \multicolumn{1}{c}{ OBJETIVOS } \\
\hline GOBIERNO SIRIO & $\begin{array}{l}\text { Mantener en el poder a la minoría } \\
\text { chií alawita, conservando así el } \\
\text { statu quo de los grupos de poder en } \\
\text { Siria }\end{array}$ & $\begin{array}{l}\text { Derrotar militarmente a los grupos } \\
\text { opositores y permanecer en el poder }\end{array}$ \\
\hline $\begin{array}{l}\text { COMBATIENTES } \\
\text { FHIITAS: HEZBOLLA, } \\
\text { MILICIAS IRAQUÍES } \\
\text { CHIITAS }\end{array}$ & $\begin{array}{l}\text { Apoyar militarmente al régimen de } \\
\text { Bashar al Assar } \\
\text { operaciones desde donde amenazar } \\
\text { y atacar a Israel. }\end{array}$ & $\begin{array}{l}\text { Siria y los grupos rebeldes que lo apoyan } \\
\text { Atacar a Israel desde sus bases en Siria }\end{array}$ \\
\hline
\end{tabular}




\begin{tabular}{|c|c|c|}
\hline ACTOR & INTERESES & OBJETIVOS \\
\hline RUSIA & $\begin{array}{l}\text { Conservar la influencia y el poder } \\
\text { del eje Irán Siria Rusia en Medio } \\
\text { Oriente. } \\
\text { Mantener su base naval en Tartus y } \\
\text { la presencia de sus fuerzas militares } \\
\text { Controlar el flujo del petróleo y gas } \\
\text { desde Medio Oriente y así controlar } \\
\text { el precio del petróleo en Europa que } \\
\text { es su mercado natural. }\end{array}$ & $\begin{array}{l}\text { Asegurar la lealtad del presidente Bashar al } \\
\text { Assad, como su aliado geopolítico. } \\
\text { Evitar que Estados Unidos o Turquía } \\
\text { instalen bases militares en Siria. } \\
\text { Incrementar el precio del petróleo y gas } \\
\text { en Europa incrementando así su PIB y por } \\
\text { tanto su poder nacional }\end{array}$ \\
\hline IRÁN & $\begin{array}{l}\text { Mantener la fortaleza del eje Irán } \\
\text { Siria Rusia en Medio Oriente. } \\
\text { Llegar a ser una potencia nuclear en } \\
\text { el mediano plazo. } \\
\text { Mantener en Siria una base de } \\
\text { operaciones desde donde pueda } \\
\text { destruir a Israel. }\end{array}$ & $\begin{array}{l}\text { Sostener en el poder a la minoría chí } \\
\text { alawita. } \\
\text { Asegurar el apoyo de Rusia a su programa } \\
\text { nuclear } \\
\text { Realizar ataques sistemáticos a Israel desde } \\
\text { una base de operaciones en Siria }\end{array}$ \\
\hline CHINA & $\begin{array}{l}\text { Asegurar su influencia en un Medio } \\
\text { Oriente y su capacidad de veto en el } \\
\text { Consejo de Seguridad }\end{array}$ & $\begin{array}{l}\text { Evitar que el Consejo de Seguridad de luz } \\
\text { verde a una intervención norteamericana. }\end{array}$ \\
\hline $\begin{array}{l}\text { GRUPOS OPOSITORES } \\
\text { SIRIOS }\end{array}$ & $\begin{array}{l}\text { Tomar el control político de Siria } \\
\text { mediante elecciones libres }\end{array}$ & Derrocar el gobierno de Bashar al Assad \\
\hline $\begin{array}{l}\text { COMBATIENTES } \\
\text { SUNIES DE ISIS }\end{array}$ & $\begin{array}{l}\text { Instalar en el gobierno a los } \\
\text { yihadistas }\end{array}$ & Derrocar el gobierno de Bashar al Assad. \\
\hline $\begin{array}{l}\text { ARABIA SAUDITA Y } \\
\text { QATAR }\end{array}$ & $\begin{array}{l}\text { Asegurar un gobierno de mayoría } \\
\text { sunita, afín a sus intereses }\end{array}$ & Derrocar al régimen de Bashar Al Assad \\
\hline ESTADOS UNIDOS & $\begin{array}{l}\text { Imponer su poder y posición } \\
\text { geopolítica en la región. } \\
\text { Fortalecer el eje EEUU- OTAN } \\
\text { Arabia Saudita en Medio Oriente } \\
\text { Disminuir la influencia Iraní en } \\
\text { Siria. }\end{array}$ & $\begin{array}{l}\text { Derrocar al régimen de Bashar Al Assad. } \\
\text { Asegurar el flujo de petróleo y gas desde } \\
\text { Medio Oriente hacia Europa } \\
\text { Derrotar a los grupos yihadistas de AL } \\
\text { QAEDA, apoyados por Irán }\end{array}$ \\
\hline TURQUÍA & $\begin{array}{l}\text { Evitar que el movimiento } \\
\text { separatista Kurdo en Siria contagie } \\
\text { al PKK en Turquía. } \\
\text { Retomar su influencia en Medio } \\
\text { Oriente y el gobierno Sirio y } \\
\text { reconstruir su relación con USA } \\
\text { Arabia Saudita, Qatar. }\end{array}$ & $\begin{array}{l}\text { Mantener a los separatistas Kurdos, } \\
\text { alejados de la frontera con Turquía } \\
\text { Derrocar al régimen de Bashar Al Assad } \\
\text { e instalar un gobierno afín a sus intereses } \\
\text { nacionales. }\end{array}$ \\
\hline ISRAEL & $\begin{array}{l}\text { Dislocar el eje Irán- Siria- Hezbolla, } \\
\text { evitando así ataques a su territorio } \\
\text { desde bases Sirias. }\end{array}$ & $\begin{array}{l}\text { Impedir que el régimen iraní entregue } \\
\text { armamento de alta tecnología al grupo } \\
\text { Hezbolla en Siria }\end{array}$ \\
\hline
\end{tabular}




\section{Análisis de los actores frente a sus intereses y objetivos}

Los resultados que se presentan a continuación se obtuvieron tomando como caso de estudio al conflicto sirio, de acuerdo al cuadro anterior y con la ayuda del software MACTOR, que permite visualizar en forma gráfica las relaciones entre actores, y entre estos y los intereses u objetivos que persiguen, todo esto para extraer importantes conclusiones en cuanto al equilibrio de poder en Medio Oriente.
Como podemos observar los actores más influyentes e independientes en el conflicto son: Estados Unidos y Rusia, mientras que los medianamente independientes son: China Turquía, Arabia Saudita / Qatar e Irán, mientras que los más dependientes son: el gobierno sirio, los combatientes Chí́es, la Coalición Nacional Siria y los combatientes Suníes.

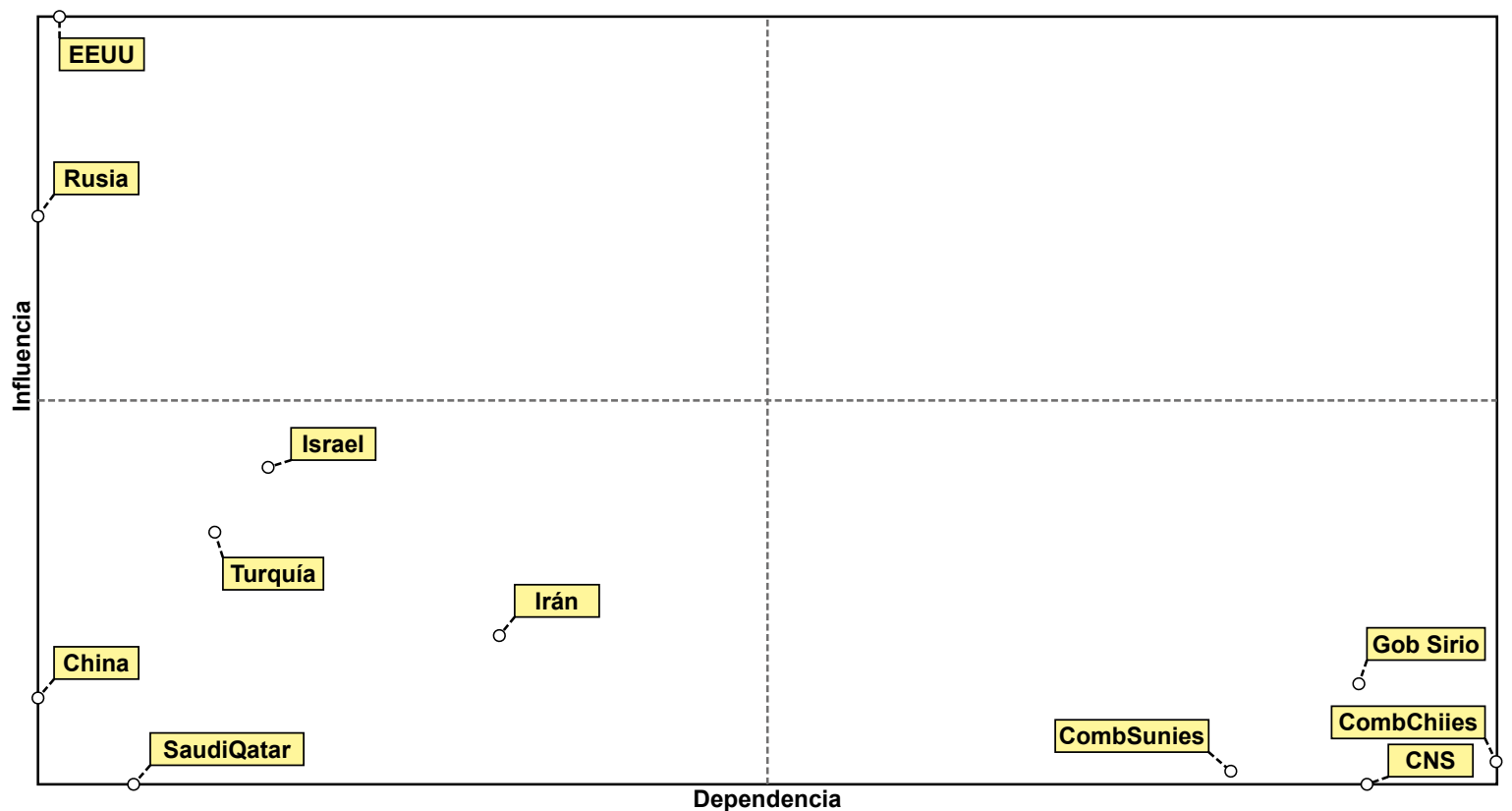

Figura 1. Plano de influencias y dependencias entre actores (Fuente: Reporte del programa MACTOR)

Esto se explica debido al inmenso poder que tienen Estados Unidos y Rusia en relación a los otros actores y la dependencia que tiene ambos bandos en el conflicto, tanto en el ámbito político económico y militar, mientras que China no está interesada en intervenir en el conflicto en forma directa. Así pues, el gobierno Sirio y sus aliados chí́es dependen del respaldo de Rusia e Irán para abastecerse de armas y del apoyo de Rusia y China para evitar que una resolución del Consejo de Seguridad de las Naciones Unidas, permita una intervención directa de Estados Unidos y sus aliados de la OTAN en el conflicto Sirio.

De igual manera la Coalición Nacional Siria depende del apoyo político, económico y militar de Estados Unidos y el financiamiento de Arabia Saudita y Qatar a través de Turquía.

Las relaciones de poder entre los actores nos reflejan que el actor más poderoso en el conflicto sirio sigue siendo los Estados Unidos, no solo por su poder nacional intrínseco, sino por el despliegue de fuerzas que ostenta en la región, a esto se suma el respaldo que tiene por parte de sus aliados de la OTAN, como es el caso actual de Turquía. Israel como actor interesado en el conflicto, se reserva su derecho de responder militarmente a los ataques que provienen de Siria con el apoyo de Irán.

Rusia por otro lado tiene un poder y tecnología militar inferior al de Estados Unidos, sin embargo la gran diferencia está en el respaldo irrestricto de la sociedad rusa y sus instituciones estatales y no estatales, lo que le permite aplicar ese poder militar en forma directa en el campo de batalla, como lo demuestra la presencia de sus unidades blindadas, armas antiaéreas, sus sistemas de misiles S-400 tierra aire y los cazabombarderos Sukhoi 27, MIG 35 y la flota de superficie que se encuentra en la base naval de Tartus en territorio Sirio. Cuenta además con el apoyo de Irán en el ámbito político, tecnológico y militar y de manera encubierta de los grupos radicales chítas en la región; como contraparte Rusia apoya el programa desarrollo nuclear iraní. 
El gráfico siguiente, resume las relaciones de poder entre los actores del conflicto:

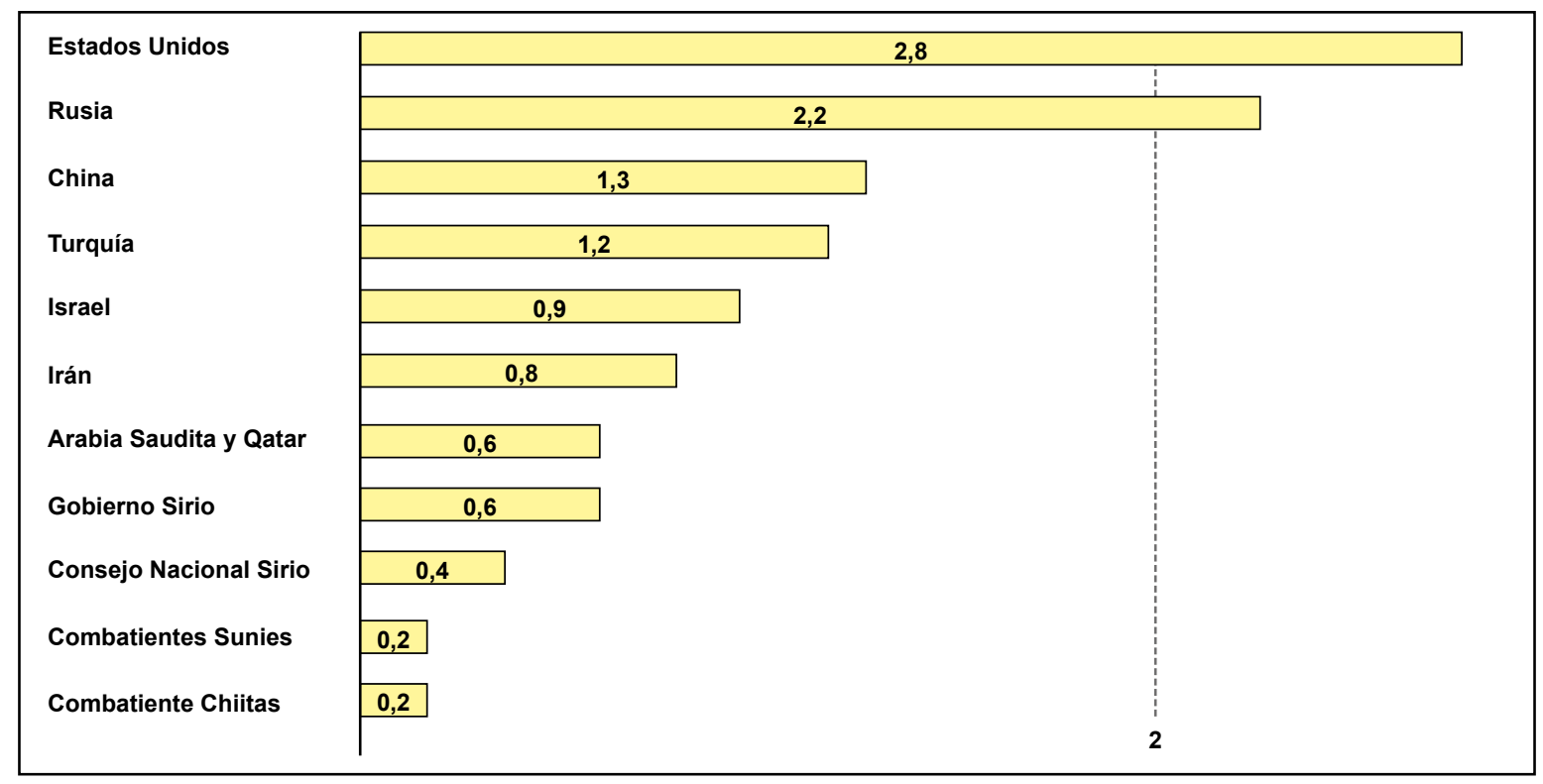

Figura 2. Histograma de relaciones de fuerza MMIDI (Fuente: Reporte del programa MACTOR)

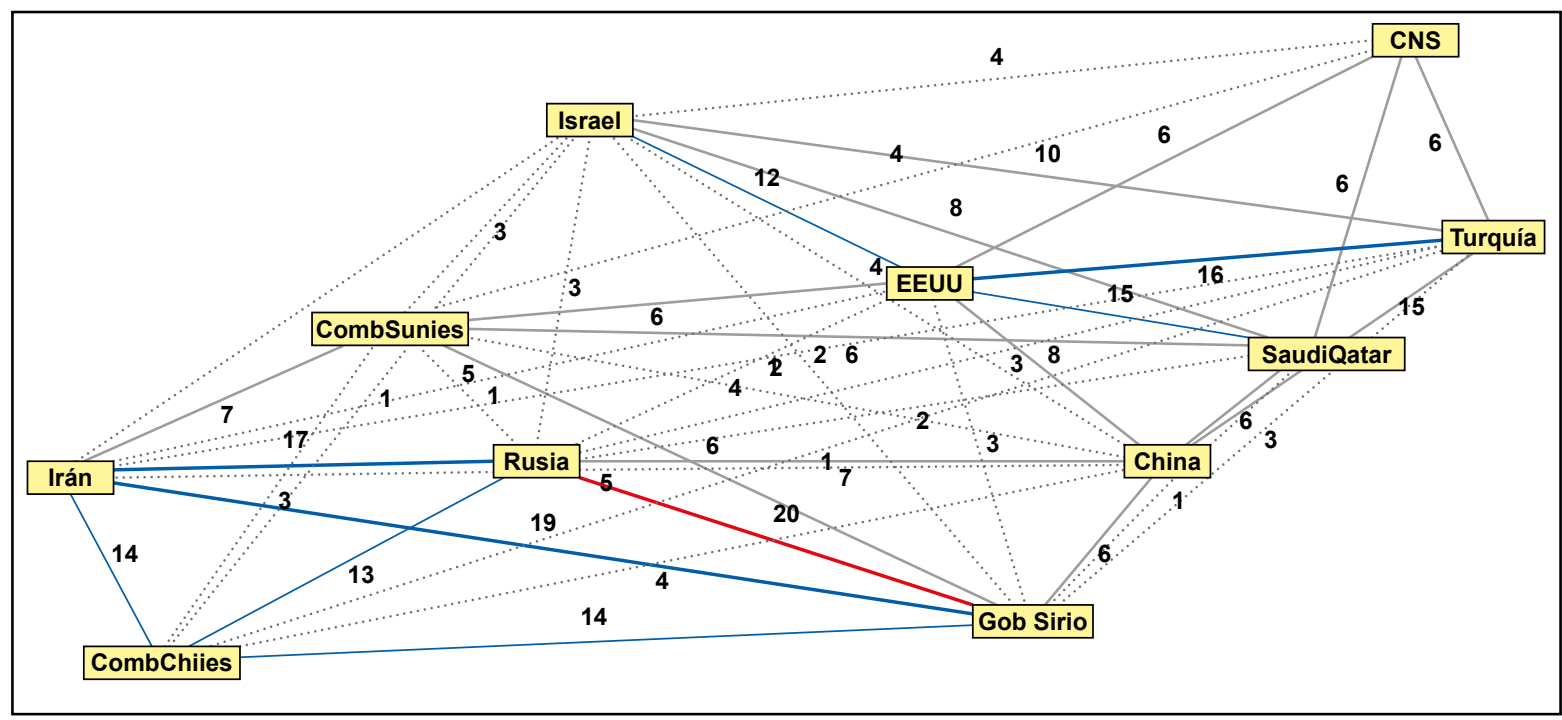

Convergencias más débiles

Convergencias débiles

- Convergencias medias

- Convergencias relativamente importantes

- Convergencias más importantes

Figura 3. Gráfico de convergencias entre actores y objetivos de orden 1

(Fuente: Reporte del programa MACTOR)

En este gráfico se pueden observar que las mayores convergencias en relación a los objetivos planteados están entre Rusia, Irán y el Gobierno Sirio, esto se explica porque su objetivo común es el de conservar en el poder al gobierno chiita de Bashar al Assad y mantener su influencia geopolítica en la región; todo esto basado en el hecho de que un cambio de gobierno hacia la mayoría sunita en Siria, significa para Rusia la pérdida de su influencia en Medio Oriente y el control del flujo de petróleo y gas hacia Europa, para Irán la pérdida de su base de operaciones para atacar a Israel, y por tanto un cambio geopolítico favorable hacia los intereses de los Estados Unidos y sus aliados de la OTAN.

De otro lado las convergencias de objetivos entre Estados Unidos y Turquía, se basan en su intención de derrocar el gobierno de Bashar al Assad, en el caso de Estados Unidos con el propósito de incrementar su influencia en la región, desarticulando el Eje Rusia Siria Irán lo que le permitiría asegurar un flujo de petróleo y 
gas hacia sus aliados europeos de la OTAN, evitando que un incremento del precio de petróleo y gas, pueda potenciar el poder nacional ruso, de forma paralela, evitar que Irán pueda desestabilizar la región y afectar los intereses de occidente mediante una guerra abierta contra Israel; mientras que Turquía como actor estra- tégico regional y mundial, busca ejercer su influencia regional, controlar el flujo migratorio de los refugiados sirios, dejando claro que no tolerará que los rebeldes Kurdos del PPK, tengan en el norte de Siria un lugar seguro para sus acciones separatistas.

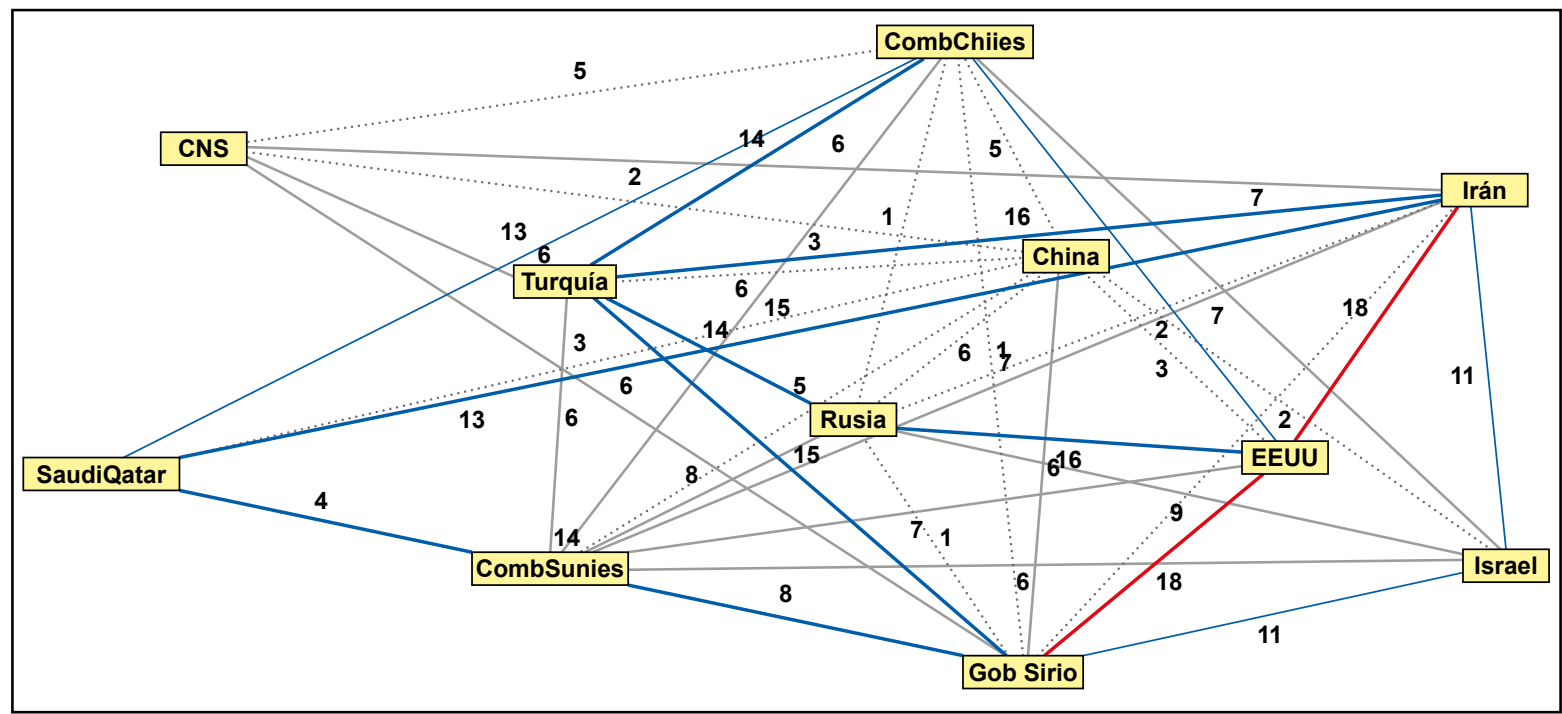

Convergencias más débiles

- Convergencias débiles

- Convergencias medias

- Convergencias relativamente importantes

- Convergencias más importantes

Figura 4. Gráfico de divergencias entre actores de orden 1

(Fuente: Reporte del programa MACTOR)

En el gráfico se observan que las divergencias más importantes se dan entre Estados Unidos con el Gobierno Sirio e Irán, esto se refleja en la actitud estratégica del primero para derrocar al régimen de Bashar al Assad y la permanente beligerancia con Irán por detener su programa de desarrollo nuclear y sus acciones desestabilizadoras en la región. Basta señalar que el ataque dirigido contra el General Qasem Soleimani, líder de la Fuerza QUDS de la Guardia Republicana Iraní, ha sido considerado por el gobierno norteamericano, como un objetivo estratégico alcanzado en Medio Oriente; evento que generó una reacción inmediata por parte de Irán y las milicias chiitas, mediante el ataque a las bases norteamericanas en la región.

Del mismo modo se identifica una divergencia importante entre el gobierno Sirio y Turquía, evidenciado por la intervención directa de las Fuerzas Armadas de Turquía en el conflicto y que ahora junto con los Grupo Opositores controla el norte de Siria, estrategia que cuenta con la aprobación encubierta del Gobierno Norteamericano, mediante la evacuación de sus unidades del territorio en donde junto a los kurdos, combatían a los grupos radicales de ISIS y AL QAEDA.

Esta actitud de Turquía responde a la amenaza que representan los flujos migratorios masivos de los refugiados sirios que huyen del conflicto, así como de las acciones de los grupos rebeldes kurdos en Siria aliados con el movimiento separatista PPK en Turquía, quienes han sido calificados como terroristas por el gobierno del presidente Tayip Erdogan y una amenaza a su Seguridad Nacional.

De otro lado la divergencia entre Arabia Saudita y Qatar frente al gobierno sirio, se explica por sí solo, pues ambas naciones árabes tiene como objetivo deponer al gobierno chiita de Bashar al Assad e instalar un gobierno de mayoría sunita, favorable a su sistema de valores e intereses en la región.

En el gráfico de convergencia de orden dos, ya se puede visualizar en forma clara la conformación de dos ejes opuestos en sus intereses y objetivos; de un lado tenemos al eje Rusia, Gobierno Sirio e Irán, quienes de manera coherente orientan sus acciones tendientes a derrotar militarmente a los grupos opositores al gobierno sirio, mantener el control del poder en manos de la minoría chita alauita en Siria, asegurar para Rusia el control del flujo de petróleo y gas hacia Europa lo que le permite controlar su precio, de otro lado Irán asegura el respaldo político y tecnológico de Rusia para su programa nuclear y mantiene una base de operaciones segura desde donde atacar a Israel, esto configura una permanencia del estatus quo en la región. 
Mientras tanto en el otro lado el eje opositor, los Estados Unidos junto a Turquía, Arabia Saudita y Qatar, persiguen el derrocamiento del gobierno sirio, y con ello asegurar un flujo controlado de gas y petróleo hacia sus aliados europeos de la OTAN y por cierto la regulación del precio de los combustibles, afectando a la economía rusa y por tanto su poder nacional. Para Turquía la salida del gobierno sirio significa el fin del flujo migratorio hacia su territorio, situación que está amenazando a su estabilidad política y económica interior, además permite controlar a las milicias kurdas aliadas del PPK, desarticulando así sus acciones separatistas. Para Arabia Saudita y Qatar significa el fin de un gobierno chiita hostil a su sistema de valores e intereses. Para Israel significaría una disminución de las amenazas a su existencia por parte de Irán. En resumen un triunfo del eje opositor implica un cambio geopolítico en el Medio Oriente favorable a los intereses de Estados Unidos, sus aliados de la OTAN y a los países de la Liga Árabe de orientación sunita.

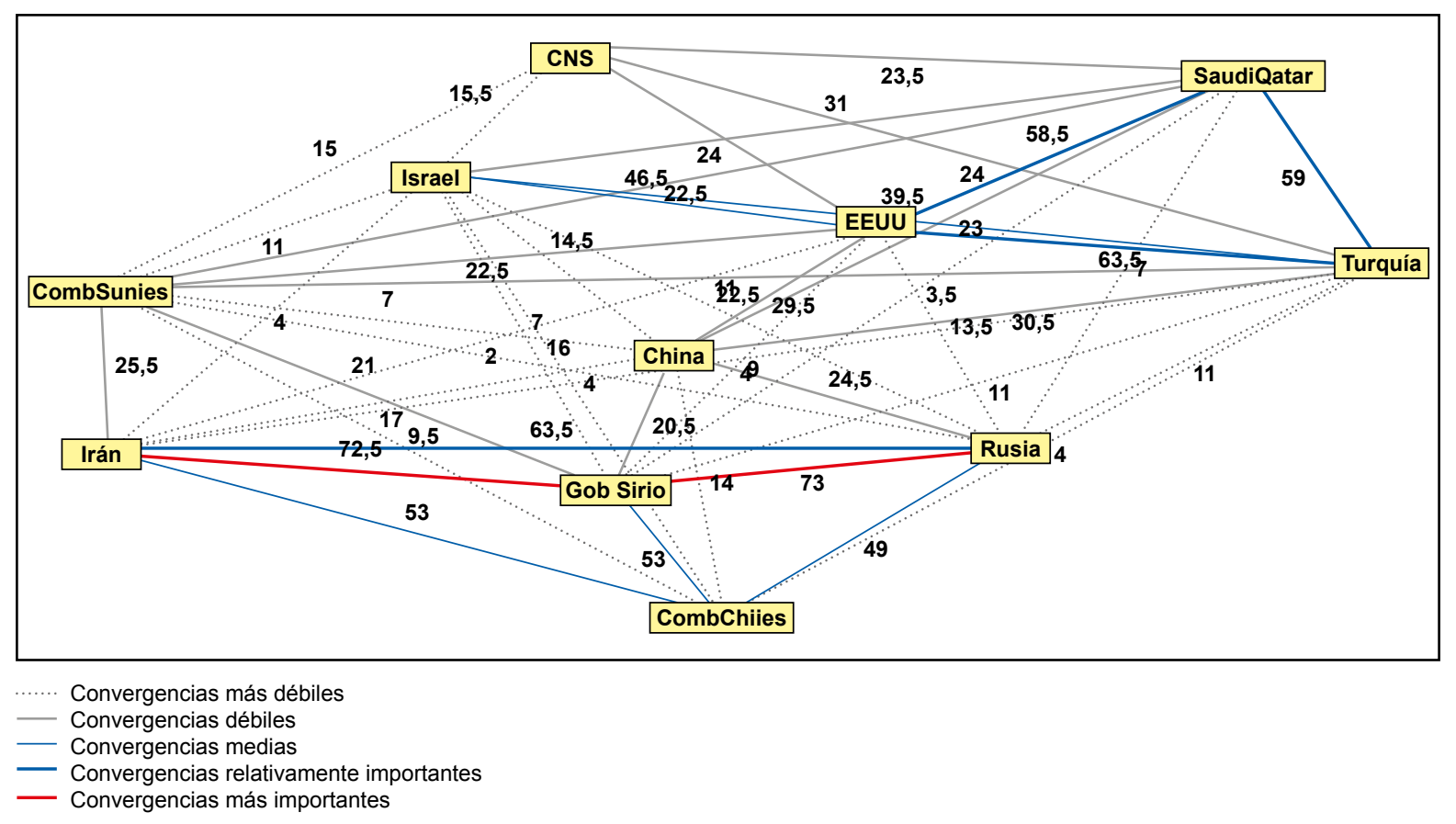

Figura 5. Gráfico de convergencias entre actores de orden 2

(Fuente: Reporte del programa MACTOR)

En el gráfico de divergencias de orden 2 se acentúan las diferencias respecto de sus objetivos entre Estados Unidos, el gobierno Sirio e Irán; debido a la negativa del gobierno Sirio de respetar los acuerdos de alto al fuego y separación de fuerzas, la limitación en el empleo de armas como las bombas de racimo y agentes químicos como fósforo blanco. Con Irán la comunicación es nula, debido a la negativa de este último de aceptar la vigilancia y control de su programa nuclear, por parte de occidente, lo que provocó la denuncia de Estados Unidos a dicho convenio, de igual manera la implementación de una estrategia de desarticulación de las milicias chiitas controladas por Irán, aplicada exitosamente con el ataque al General Qasem Soleimani en Iraq.

En segundo lugar, se incrementan las divergencias entre Turquía frente al Gobierno Sirio, Rusia e Irán, en especial debido al pacto entre el gobierno de As- sad con los separatistas kurdos, que les ha permitido controlar la frontera norte y exaltar a los separatistas kurdos a quienes Turquía había conseguido sentar en la mesa de negociaciones. A pesar de que existe un canal de comunicación con Rusia, éste último no puede asegurar que los acuerdos a los que lleguen en forma bilateral, sean respetados por parte del gobierno sirio, situación que podría provocar el escalamiento de las acciones militares por parte de las fuerzas armas de Turquía y Siria.

También se acentúan las divergencias entre Arabia Saudita Qatar e Irán, esto se explica por el interés de los países árabes por llevar al gobierno a los sunitas salafistas, que les permita llevar el equilibrio estratégico en Medio Oriente, hacia la Liga Árabe y dejar en solitario a Irán e Iraq como los últimos bastiones chiitas en la región. 


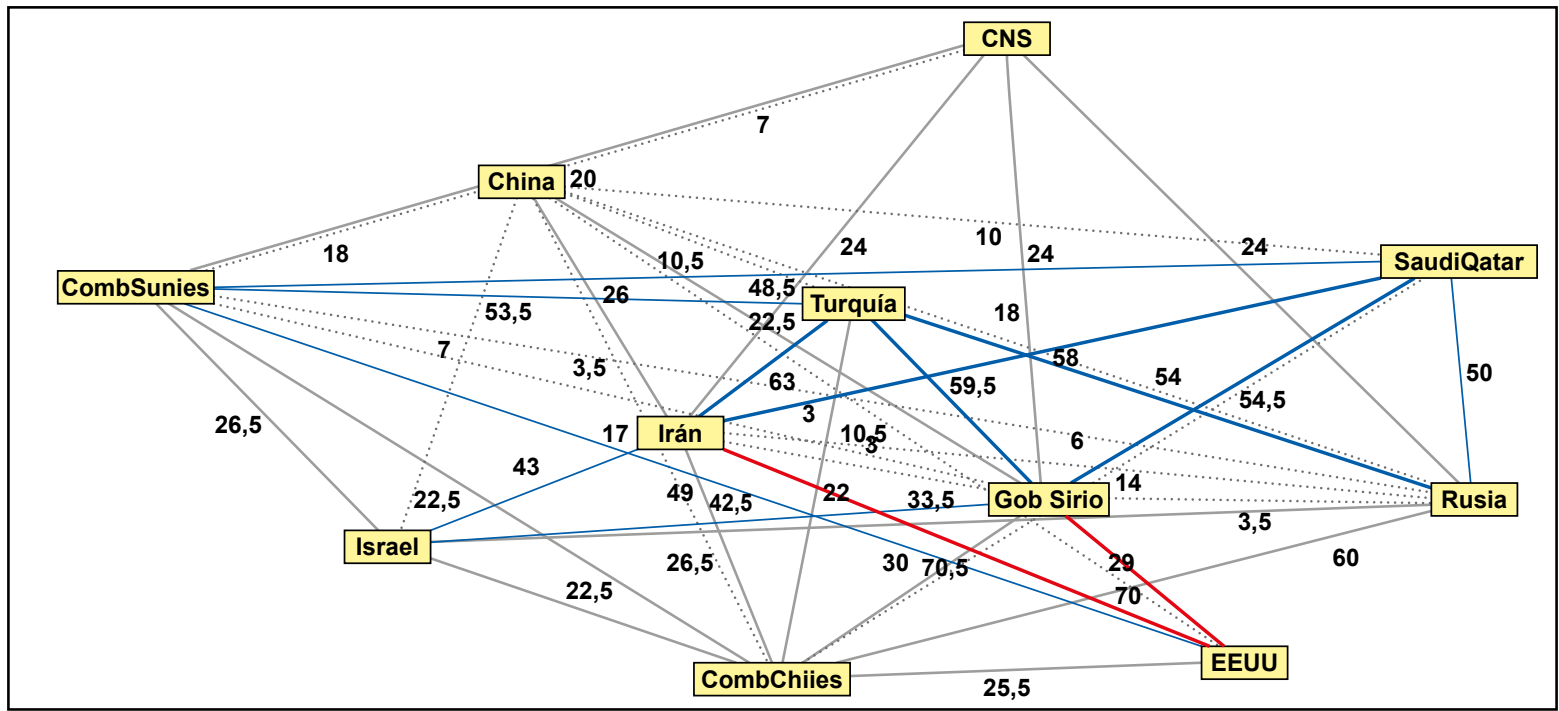

Convergencias más débiles

Convergencias débiles

Convergencias medias

- Convergencias relativamente importantes

- Convergencias más importantes

Figura 6. Gráfico de divergencias entre actores y objetivos de orden 2

(Fuente: Reporte del programa MACTOR)

\section{Escenarios futuros}

Las variables a considerar en el análisis son: La orientación étnico religiosa del gobierno sirio, la influencia de Occidente en Medio Oriente, la Influencia Ruso-Iraní en Medio Oriente, la beligerancia de los actores hacia Israel.

De acuerdo al análisis realizado se visualizan dos escenarios posibles:

Escenario probable de mantenimiento del Stato quo:

El gobierno de Bashar al Assad y sus fuerzas armadas, con el apoyo directo de Rusia e Irán y el bloqueo en el Consejo de Seguridad de la ONU por parte de China y Rusia se mantiene en el poder y consolida su posición política y militar en Siria; desplazando a miles de refugiados civiles de origen sunita y de los opositores beligerantes hacia la faja de seguridad en el norte de Siria, acordada en las conversaciones entre Rusia y Turquía agravando así la crisis humanitaria, que actualmente genera más de tres millones de refugiados que ya se encuentran en Turquía y que serían desplazados hacia la zona de seguridad en el norte de Siria. Rusia mantiene el control del flujo de petróleo y gas de Medio Oriente a Europa a través de los oleoductos sirios y por tanto controla el precio de los combustibles en dicho mercado, incrementando así su influencia geopolítica y poder regional; sus relaciones con Irán se fortalecen aún más, mediante el apoyo político y tecnológico a su programa nuclear. Irán y Siria continúan apoyando militarmente a la milicia de Hezbolla para atacar objetivos en Israel, manteniendo así el statu quo el eje Rusia-Siria-Irán en el Medio Oriente.
Escenario de escalada del conflicto

El gobierno de Bashar al Assad y sus fuerzas gubernamentales, desconocen el acuerdo entre Rusia y Turquía y por tanto la zona de seguridad establecida en el norte de Siria, desplazando a buena parte de la población hacia Turquía, generando un flujo masivo de migrantes hacia Europa a través de Turquía; como respuesta, las Fuerzas Armadas de Turquía incrementan significativamente sus fuerzas en el conflicto, generando una escalada bélica que obliga a Estados Unidos y sus aliados de la OTAN a intervenir en la guerra.

Las acciones escalan en intensidad y Medio Oriente vuelve a ser un escenario de un conflicto regional, en el que se ven involucrados directamente las fuerzas armadas de Turquía apoyados por sus aliados de la OTAN frente a las fuerzas gubernamentales de Siria apoyadas directamente por las fuerzas armadas de Rusia e Irán.

El mundo reedita una confrontación Este-Oeste que no habíamos visto desde el fin de la Guerra Fría, sin embargo, ahora las circunstancias son más delicadas debido a la intervención directa de las fuerzas rusas en el campo de batalla, frente a un apoyo timorato de Estados Unidos hacia las fuerzas beligerantes, ahora lideradas por Turquía.

Rusia mantiene el control del flujo de gas y petróleo hacia Europa y presiona para un incremento de los precios, de forma paralela se refuerza su relación política tecnológica con Irán y por tanto su apoyo al programa de desarrollo nuclear. 
Una escalada del conflicto podría provocar un ataque de las milicias chiitas pro iraníes hacia Israel desde su base de operaciones en Siria, todo esto provocaría una gran inestabilidad regional y mundial.

El gran perdedor geopolítico en cualquiera de los dos escenarios será Estados Unidos, pues ha tenido que retirar todas sus fuerzas de Siria, no ha conseguido remover al presidente Bashar al Assad de su cargo, se habrá fortalecido el eje Rusia Siria Irán y ahora Rusia está en capacidad de controlar el flujo de petróleo y gas a Europa y por tanto el precio de la energía en un mercado al que abastece de manera permanente y del que depende buena parte de sus ingresos y por ende su poder nacional.

Israel ve amenazada su seguridad por el incremento de los ataques de las milicias Chiitas hacia su territorio y su respuesta podría desencadenar ataques iraníes directos desde bases sirias.

Los socios europeos de la OTAN ven con preocupación que Rusia una vez más imponga sus intereses con el uso de la fuerza en forma directa y aunque su poder militar es inferior al de Estados Unidos, su fortaleza radica en la cohesión nacional de sus ciudadanos, su identidad nacional y la ausencia de oposición política. La sociedad rusa ve al presidente Putin como un líder de talla mundial, que es capaz de situar a Rusia como la primera potencia militar en el mundo, no solamente por los medios que dispone, sino por la voluntad de emplearlos sin restricciones con absoluta coherencia y apoyo nacional.

Esta realidad es completamente distinta en el lado norteamericano, en donde la política nacional esta polarizada entre demócratas y republicanos, el cuestionamiento permanente a las decisiones del presidente Trump, nos muestran una sociedad dividida sin un liderazgo efectivo, que pueda retomar la posición hegemónica que ocupó luego de la disolución de la Unión Soviética.

Europa y en especial los aliados europeos de la OTAN, tendrá que pensar en desarrollar sus capacidades militares en forma autónoma, pues ya no confía en la capacidad de resolución y el poder militar de Estados Unidos, por tanto, deberán dedicar ingentes recursos a construir un poder regional, que les permita poner un freno a las ambiciones rusas en la región.

Las víctimas más sensibles de este conflicto, son los millones de refugiados sirios de origen suní, que han perdido sus hogares y no tendrán a donde regresar, puesto que el vencedor estará dispuesto a castigarlos a su re- torno y quedarán abandonados a su suerte en campos de refugiados; abandonados a su suerte y en condiciones de vulnerabilidad no tendrán otra opción que conformar los cinturones de miseria en las principales capitales europeas y tendrán que acostumbrarse a los sacrificios y privaciones de una economía de supervivencia. Las inversiones necesarias para reconstruir Siria son inmensas y ninguno de los actores está en capacidad y disposición de financiar la reconstrucción del país, esta es una tarea titánica para cualquier gobierno a futuro.

Otro gran perdedor es la Organización de las Naciones Unidas, pues ninguno de sus exhortos fue acogido por las partes, se muestra como una organización de papel, incapaz de asegurar un ambiente de paz y cooperación en el mundo, una institución carente de todo poder de decisión o influencia en el manejo y resolución de conflictos.

Estos escenarios nos plantean las inferencias fundamentales: ¿Cómo mantener el equilibrio y estabilidad en la región?, y ¿Cómo contener los vientos de la guerra? Estados Unidos no puede darse el lujo de conservar su histórica postura ambivalente, pues, los potenciales actores sucesores del conflicto en la región lo han declarado abiertamente como su principal enemigo; por ello, se requiere una política activa norteamericana, que no busque imponer por la violencia un orden regional, en base a valores universales sino uno basado en el equilibrio entre legitimidad, poder e interés nacional que evidentemente para el caso de Oriente Medio será imperfecto.

Definir un nuevo esquema de cooperación puede ser trascendental y poner sobre la mesa de debate geopolítico estadounidense la posibilidad de estrechar vínculos con Rusia, quien hasta el momento no tiene claro cuál debe ser el alcance de su participación en el conflicto por el peligro que representa para su seguridad interior, la presencia del extremismo religioso, en las repúblicas islámicas que rodean a su territorio.

La paz y el orden basados en principios democráticos tiene etapas intermedias que requieren hábiles y claras líneas de acción estratégicas, el apoyo subrepticio a facciones extremistas de corte ideológico, religioso o económico, por parte de grandes potencias no acarreará otra cosa que el caos y la anarquía. Por ello, se vuelve fundamental un orden mundial multipolar, con el suficiente poder político y militar que pueda intervenir efectivamente entre los beligerantes, para ello es necesario repensar el proceso de toma de decisiones del Consejo de Seguridad de las Naciones Unidas, en especial el poder de veto de cada uno de sus miembros.

\section{REFERENCIAS}

[1] Wikipedia. (2020). Siria. abril 30, 2020, de Divulgación Científica Sitio web: Siria http://es.wikipedia.org/ wiki/Siria
[2] southfront.org. (febrero 15, 2020). MILITARY SITUATION IN SYRIA ON FEBRUARY 15, 2020 (MAP UPDATE). abril 30, 2020, de Divulgación Científica Sitio web: https://southfront.org/wp-content/ uploads/2020/02/15feb_Syria_war_ map.jpg
[3] Lipsor (2003), MACTOR 2.0 [Software], http://www.3ie.org/lipsor/ micmac.htm. 